\title{
Retention in the Austrian opioid agonist treatment system: a national prospective cohort study
}

\author{
Martin Busch ${ }^{1}$, Charlotte Klein ${ }^{1}$, Alfred Uhl ${ }^{1,2}$, Hans Haltmayer ${ }^{3}$, Maurice Cabanis ${ }^{4}$, \\ Jean Nicolas Westenberg ${ }^{5,7^{*}}$ (D, Marc Vogel ${ }^{6}$ and R. Michael Krausz ${ }^{5}$
}

\begin{abstract}
Background: Retention in care is a prerequisite for successful recovery, especially for a chronic condition like opioid dependence. Though retention varies greatly depending on the different substitution medication and treatment model, treatment retention is used as an indicator of treatment quality and effectiveness of care on a system and individual level. To monitor the overall quality of the Austrian opioid agonist treatment (OAT) system and to monitor patient satisfaction within the system, a new online-based registry called "eSuchmittel" was introduced in Austria at the beginning of 2011. The objective of this study is to analyze retention rates within the Austrian treatment system and to identify patient characteristics associated with retention, using data collected by the substitution registry.
\end{abstract}

Methods: The complete Austrian sample of 4778 registered patients starting treatment between 1.1.2011 to 31.12.2012 were included in the prospective cohort study using data from the Austrian substitution registry. For the statistical analysis, multivariate Cox Regression and Kaplan-Meier survival analysis were used to evaluate retention in treatment.

Results: The retention rate of the total cohort after two years was around $61 \%$. Retention rates were significantly lower for men $(\exp (B)=.806,95 \% \mathrm{Cl} 0.714-0.908)$ and significantly higher for patients aged 30 and older $(\exp (B)=1.155,95 \% \mathrm{Cl} 1.044-1.279)$, among patients located in Vienna $(\exp (B)=1.439,95 \% \mathrm{Cl} 1.273-1.626)$ and among patients prescribed oral slow-release morphine (SROM) $(\exp (B)=2.141,95 \% \mathrm{Cl} 1.885-2.430)$.

Conclusions: Average retention in the Austrian system is high in comparison to international retention rates. Nationally, SROM demonstrates higher treatment retention when compared to other available substitution medications. Sociodemographic and regional indicators also contribute to higher retention in care. A systematic monitoring of retention rates within a national registry is an important tool helping to evaluate the quality of care. In this study, the Austrian OAT system proves very high retention in care, an important success criterion.

Keywords: Opioid use disorder, Opioid agonist treatment, Treatment retention, Slow-release morphine, National registry

*Correspondence: jean.westenberg@alumni.ubc.ca

${ }^{5}$ Department of Psychiatry, University of British Columbia, Vancouver, Canada

Full list of author information is available at the end of the article

\section{Introduction}

Opioid agonist treatment (OAT) is the most effective evidence-based treatment strategy for opioid dependence, and contributes to outcomes like psychosocial stabilization, reintegration into society and reduction of drug related mortality [1-5]. Other well-documented outcomes of OAT include reduction of high-risk drug use, original author(s) and the source, provide a link to the Creative Commons licence, and indicate if changes were made. The images or other third party material in this article are included in the article's Creative Commons licence, unless indicated otherwise in a credit line to the material. If material is not included in the article's Creative Commons licence and your intended use is not permitted by statutory regulation or exceeds the permitted use, you will need to obtain permission directly from the copyright holder. To view a copy of this licence, visit http://creativecommons.org/licenses/by/4.0/. The Creative Commons Public Domain Dedication waiver (http://creativeco mmons.org/publicdomain/zero/1.0/) applies to the data made available in this article, unless otherwise stated in a credit line to the data. 
reduction of criminal activities and prevention of drug related infectious diseases [6-8].

Overall retention in treatment constitutes a broadly accepted indicator which is used to evaluate the quality of OAT [9-11]. Retention in OAT significantly reduces the risk of all-cause mortality and overdose mortality for those dependent on opioids, whereas poor retention and dropping out of treatment has been shown to increase mortality risk [12]. Additionally, the mortality risk is much higher in the first four weeks of treatment than in the remainder of treatment, and is significantly reduced provided the duration of substitution treatment exceeds one year $[12,13]$ Further analyses have also shown that patients staying in treatment for a year or longer were nearly five times more likely to have better outcomes, and that length of treatment stay was predicted by higher patient motivation at intake and early program involvement [14]. Positive treatment outcomes such as treatment completion or longer treatment retention have also been related to greater service intensity and quality [15]. These results underline the special importance of OAT retention length towards treatment outcome, as well as the relationship between quality of care, treatment retention, and patient outcome.

A systematic review found a wide range of retention rates in OAT among randomized controlled trials (RCTs) at 3 months (19.0-94.1\%), 4 months (45.9-91.9\%), 6 months (3.0-88.0\%), and 12 months (37.0-90.7\%) [16]. Similarly, non-RCT studies also found a wide range of retention at 3 (68.0-87.0\%), 6 (21.4-78.1\%), or 12 (26.0-85.0\%) months [16]. Median retention rate across all studies has been found to be approximately $58 \%$ at 12 months and $38.4 \%$ at three years, with methadone cohorts reporting higher median retention rate at 6 and 12 months compared to buprenorphine cohorts and mixed OAT cohorts [17]. This is consistent with previous studies suggesting that buprenorphine is associated with shorter duration of treatment relative to methadone [17, 18]. In a meta-analysis comparing methadone to slowrelease oral morphine (SROM), the difference in dropouts was not statistically significant between participants receiving either medication [19].

Along with type of substitution medication, factors related to the dose, prior treatment experience, and treatment readiness have all been associated with an individual's treatment retention [17, 20-23]. Similarly, sociodemographic factors such as age, gender, marital status, employment, ethnicity, as well as health-related factors such as physical health, mental health, addiction severity, suicide attempts and polysubstance have been found to contribute to retention in treatment $[17,20,21$, 23-27]. For instance, younger age, substance use, lower doses, criminal activity, and negative attitudes towards treatment appear to be associated with reduced retention in OAT [17].

OAT was officially implemented in Austria in 1987 [28]. In the beginning, access to OAT was quite limited (e.g. failed trials of abstinence orientated treatment, HIV infection, pregnancy) but these restrictions have since disappeared, and OAT has become the most important treatment option for opioid dependence in Austria [28]. It is estimated that between 50 and $60 \%$ of individuals with opioid use disorder are in OAT in 2019 [29]. Methadone was originally the only substitution medication available, but SROM was added in 1998, buprenorphine in 1999 and buprenorphine/naloxone in 2008 [28]. In 2018, 55\% of patients were treated with SROM, 19\% with buprenorphine, $11 \%$ with methadone, and $13 \%$ with methadone/ levomethadone [29]. Almost all OAT medications are covered by health insurances and can be initiated by general practitioners who have completed a special training and who continue to attend regular trainings to keep up-to-date [30]. General practitioners play an important role in OAT in Austria: 73\% of OAT patients were treated by general practitioners in 2019 [29]. Other licenses also exist to allow other general practitioners to maintain OAT, but without the ability to change the dosage or medication [30]. Prescription of substitution medication is controlled nationally, and the medication is dispensed in pharmacies on a daily basis and consumed under observation by the pharmacists. There are exceptions however, such as take-home doses for the holidays as well as for patients who are very well integrated and stable. All substitution prescriptions are regulated by the Austrian Narcotics Act [31] and related decrees [32].

The Austrian substitution registry was set up and has been maintained by the Federal Ministry of Health since 1989, when opioid agonist treatment was officially implemented. Physicians were asked to notify the registry about the beginning and end of each of their patient's substitution treatment in order to prevent patients from being treated by more than one physician at the same time. At the beginning, the quality of the data was limited due to the fact that the completeness of the registry could not be assumed. In particular, the registry was not systematically informed about a certain percentage of treatment terminations, resulting in an increasing number of "ghost cases" in the registry. These were generated when patients did not show up to appointments, and therefore did not provide physician with a formal treatment termination. An important step to improve data quality was made in 2008, when public health officers supervising every substitution treatment became involved in the registration procedure by supervising every OAT prescription. Public health officers were required to validate each long-term OAT prescription at least monthly. At the 
same time, the Federal Ministry in Austria started quality checks of the data and systematically eliminating ghost cases.

At the beginning of 2011, a new online-based system called "eSuchmittel" was introduced in order to assure completeness and quality of the registry. Since then, each patient entered in the OAT registry is identified via the central population registry, preventing double entries. In the process of setting up eSuchtmittel, all existing entries were systematically quality checked and, if necessary, corrected. In addition, several tools and mechanisms have been implemented to ensure continuous data quality. The data are pseudonymized for statistical analysis, while still including relevant information such as year of birth, sex, substitution medication, initial dose prescribed and region.

The objective of this study was to analyze the retention rates in the Austrian OAT system, to explore the differences between the various substitution medications, and to identify patient characteristics associated with retention, all using data collected by the newly implemented Austrian registry.

\section{Methods}

\section{Study sample}

For the present analysis, data from all patients starting OAT between 01/01/2011 and 31/12/2012, and therefore registered in the new online-based system called eSuchmittel, were used, and this cohort was followed until $30 / 04 / 2013$. The data used for this analysis includes 4,778 patients for a total of 5,165 treatment sequences. Each treatment sequence represents an independent OAT episode that was started within the analysis period by a patient registered in the registry and that was ended due to treatment discontinuation or due to study completion (end of analysis period). If the registry revealed two treatment episodes for the same patient which were no more than one month apart, these episodes were aggregated into one single treatment sequence. Treatment was actually uninterrupted for these sequences, these artificial separations appear in the registry if patients moved to another region, changed physicians or institution, etc. This is common procedure in studies using registry data [11]. If patients started a new treatment more than one month later, this was treated as a new independent sequence. The overwhelming majority of patients had only a single treatment sequence ( $92.8 \%$; Table 1$)$.

\section{Measures}

From the administrative records of patients accessing opioid substitution treatment in Austria between January 2011 and December 2012, demographic characteristics such as sex, age, as well as region and substitution medication used were extracted to assess their association with treatment retention. All the data used in this study were inputted into the system by public health officers at the start of treatment and kept up to date at each follow-up. For the analysis of regional treatment, the most recent information was used (Additional file 1: Table 1). For example, if the patient moved to Vienna from another region, the patient was counted as a Viennese patient. Moreover, for each patient, the most current medication enlisted in the system was used to determine the appropriate medication cohort. For instance, if the patient's medication changed from buprenorphine to methadone, the client was assigned to the methadone group. Of note, changes in medication were rare in the cohort-only $16 \%$ of the treatment sequences reporting a change. The proportion of substitution medication at the start of treatment sequences are almost the same as at the end of treatment sequences (Table 1).

\section{Statistical analysis}

Since the observation times were different for the individuals entering OAT, ranging between 120 and 851 days, an analysis method was needed to adequately deal with censored data. The database holds no left censored data since only patients that entered during the observation period were included, whereas patients already in treatment when the observation period started were not included. However, the database has right censored data since patients may die or move away and/or stop treatment without notifying public health officers. KaplanMeier survival and Cox regression analyses were used to compensate for right censorship as these are adequate methods to estimate cumulative dropout risk at different follow-up times [33]. The Tarone-Ware test was used in conjunction with the Kaplan-Meier curves; a multivariate Cox model was calculated using the variables available, namely age, sex and substitution medication. The database holds no information on illicit opioid of choice, history of injection drug use, education and socioeconomic status, so these could not be added to the model. These analyses were performed with the SPSS 17.0 program package [34].

\section{Ethics and study design}

All data are collected according to the Federal Austrian Narcotic Act, which explicitly states that scientific analyses with these data may be performed on behalf of the Ministry of Health. Moreover, the Austrian Public Health Institute is owned by the Austrian Ministry of Health and regulated by federal law. The Austrian Public Health Institute performs statistical analyses for the Ministry of Health. This study was therefore carried out by the Austrian Public Health Institute and was approved by the 
Table 1 Characteristics of all 4778 patients in the cohort

\begin{tabular}{|c|c|c|c|}
\hline Characteristics & & & \\
\hline \multicolumn{4}{|l|}{ OAT sequences } \\
\hline Patients with 1 sequence & \multicolumn{3}{|l|}{$92.8 \%$} \\
\hline Patients with 2 sequences & \multicolumn{3}{|l|}{$6.4 \%$} \\
\hline Patients with 3 sequences & \multicolumn{3}{|l|}{$0.7 \%$} \\
\hline Patients with 4 sequences & \multicolumn{3}{|l|}{$0.08 \%$} \\
\hline \multicolumn{4}{|l|}{$\operatorname{Sex}(\%)$} \\
\hline Male & \multicolumn{3}{|l|}{$75.0 \%$} \\
\hline Female & \multicolumn{3}{|l|}{$25.0 \%$} \\
\hline \multicolumn{4}{|l|}{ Age when treatment started } \\
\hline$<20$ & \multicolumn{3}{|l|}{$4.8 \%$} \\
\hline $20-24$ & \multicolumn{3}{|l|}{$25.7 \%$} \\
\hline $25-29$ & \multicolumn{3}{|l|}{$27.9 \%$} \\
\hline $30-39$ & \multicolumn{3}{|l|}{$27.2 \%$} \\
\hline$>39$ & \multicolumn{3}{|l|}{$14.4 \%$} \\
\hline \multicolumn{4}{|l|}{ Region } \\
\hline Vienna & \multicolumn{3}{|l|}{$28 \%$} \\
\hline Other Austrian federal states & \multicolumn{3}{|l|}{$72 \%$} \\
\hline Substitution medication & & Start of sequence & End of sequence \\
\hline Methadone & & $23.2 \%$ & $20.5 \%$ \\
\hline Levo-methadone & & $6.9 \%$ & $8.4 \%$ \\
\hline Buprenorphine & & $25.9 \%$ & $24.3 \%$ \\
\hline Buprenorphine/naloxone & & $5.7 \%$ & $5.0 \%$ \\
\hline Slow-release morphine & & $36.2 \%$ & $39.9 \%$ \\
\hline Other & & $1.1 \%$ & $1.4 \%$ \\
\hline Unknown & & $1.0 \%$ & $0.5 \%$ \\
\hline
\end{tabular}

Austrian Ministry of Health. This study is reported following the Strengthening the Reporting of Observational Studies in Epidemiology (STROBE) guidelines [35].

\section{Results}

The characteristics of the patients entered into the study are documented in Table 1. Overall, 4,778 patients were included, the majority of which were male (75\%). Patients age at the beginning of treatment seemed mostly split between the following 3 age groups: $20-24$ years old (25.7\%), 25-29 years old (27.9\%) and 30-39 years old (27.2\%). At the most recent time point, $28 \%$ of patients were located in Vienna and the rest in other Austrian federal states. Slowrelease morphine, buprenorphine, and methadone represent the 3 most common substitution medication within the Austrian treatment system.

\section{Differences in sex}

The retention rates between males and females were significantly different, as demonstrated by the KaplanMeier curves $\left(\chi^{2}=13,815, \mathrm{df}=1, \mathrm{p}<0.001\right.$; Fig. 1). Male patients had a significantly lower retention rate when compared to female patients, as demonstrated by the multivariate Cox regression model $(\exp (B)=0.806,95 \%$ CI 0.714-0.908; Table 2).

\section{Differences in age}

In Austria, the mean age of patients first entering treatment for heroin use is 29 years old [36]. By using 30 years of age for simplicity, patients were grouped as either "above 30 years old" or "below 30 years old. This dichotomous variable was then assessed based on retention. Analysis of the survival curves demonstrated significant differences between retention rates $\left(\chi^{2}=6,722, \mathrm{df}=1\right.$, $\mathrm{p}<0.01$; Fig. 1). The Cox regression revealed that older patients were more likely to be retained than younger patients $(\exp (B)=1.155,95 \%$ CI 1.044-1.279; Table 2).

\section{Regional differences}

Since Vienna is the only metropolitan city in Austria, it makes sense to compare Vienna with the rest of Austria. The retention rate of individuals living in Vienna was significantly different to those living in other parts of Austria $\left(x^{2}=46,455, \mathrm{df}=1, \mathrm{p}<0.001\right.$; Fig. 1$)$. From the 
a Retention rate by sex $\left(\chi^{2}=13,815, \mathrm{df}=1, \mathrm{p}<.001\right)$

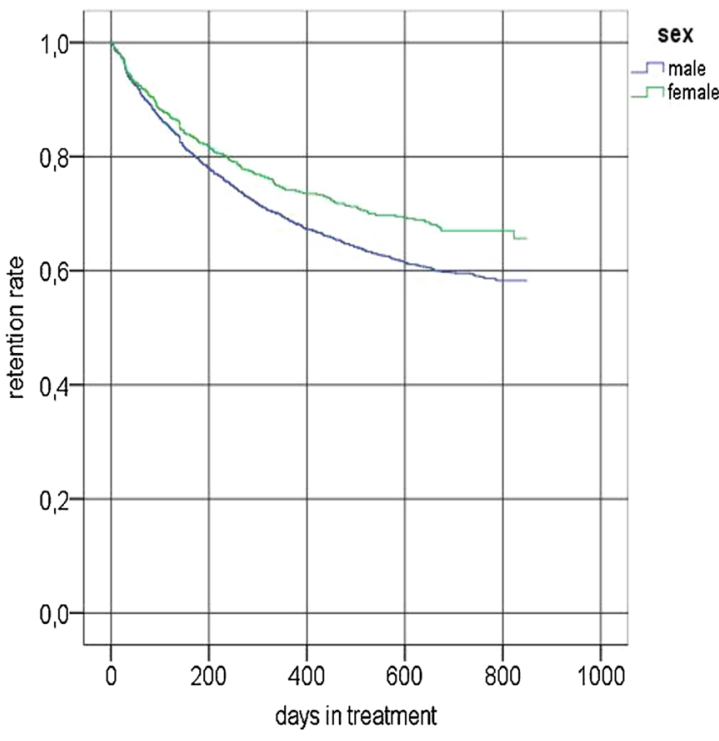

c Retention rate by region $\left(\chi^{2}=46,455, \mathrm{df}=1, \mathrm{p}<.001\right)$

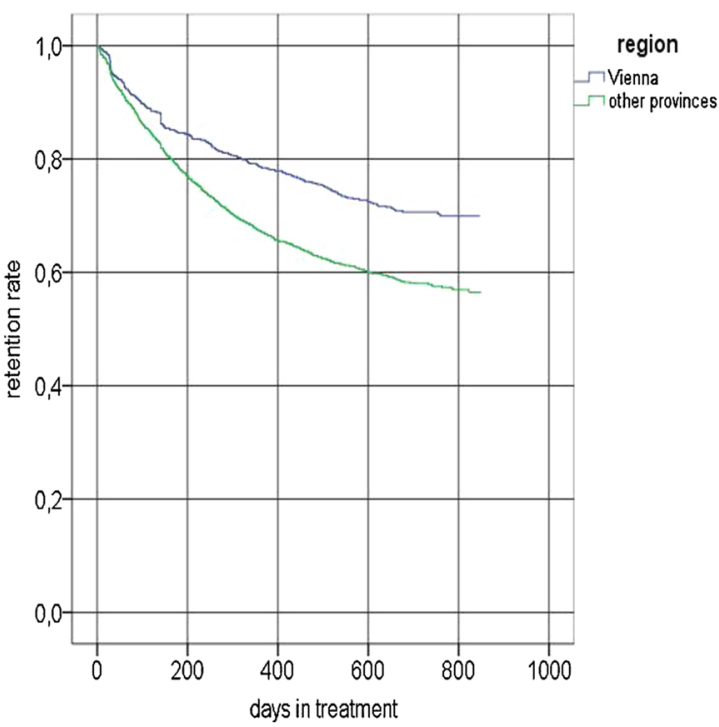

b Retention rate by age $\left(\chi^{2}=6,722, \mathrm{df}=1, \mathrm{p}<.01\right)$

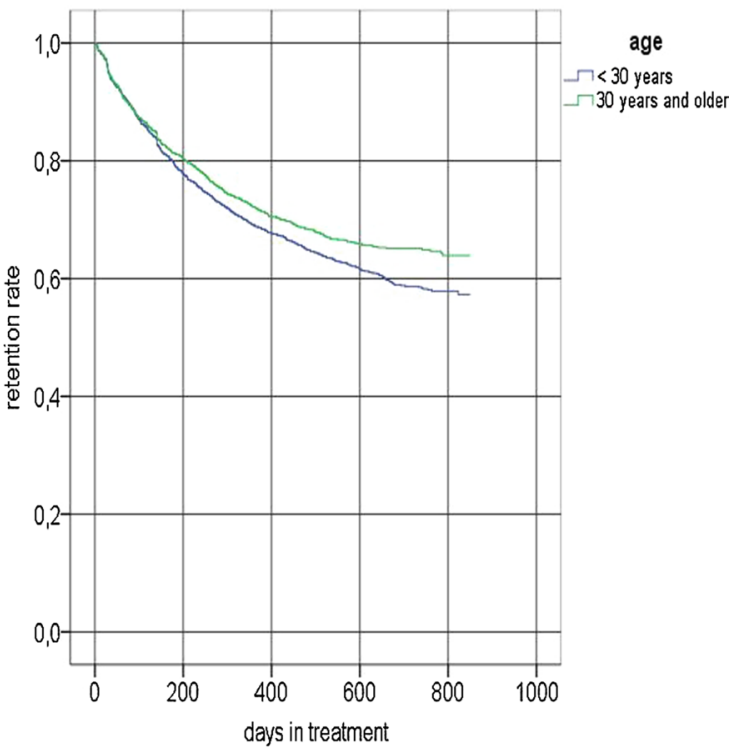

d Retention rate by medication $\left(\chi^{2}=194,559, \mathrm{df}=1, \mathrm{p}<.001\right)$

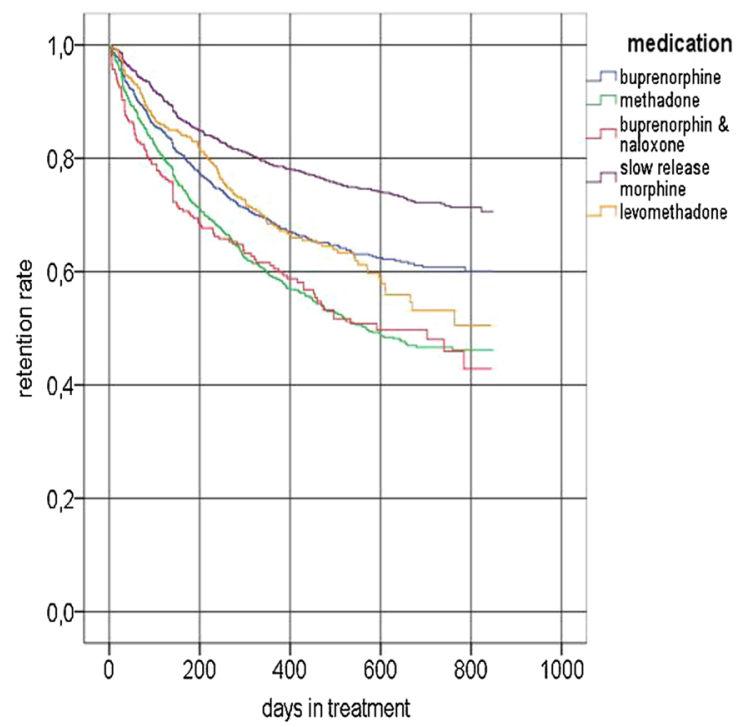

Fig. 1 Kaplan-Meier curves of retention in treatment by sex (a), age (b), region (c) and substitution medication (d), in conjunction with TaroneWare test

Cox regression model, those living in Vienna has a significantly higher retention rate $(\exp (B)=1.439,95 \%$ CI 1.273-1.626; Table 2).

\section{Differences in medication used}

From the Kaplan-Meier curves, major differences in retention rates based on substitution medication can be observed. The Tarone-Ware test demonstrate these differences are significant $\left(x^{2}=194,559, \mathrm{df}=1, \mathrm{p}<0.001\right.$; Fig. 1). The retention rate was significantly higher when slow-release morphine was prescribed $(\exp (\mathrm{B})=2.141$, 95\% CI $=1.885-2.430$; Table 2). The two-year retention rate was lowest for methadone (47\%) and 
Table 2 Multivariate Cox regression model of retention in treatment by sex, age, region and substitution medications

\begin{tabular}{|c|c|c|c|c|c|c|c|}
\hline Variables & $B$ & SE & Wald & $d f$ & Significance & $\operatorname{Exp}(B)$ & $95 \% \mathrm{Cl} \operatorname{Exp}(B)$ \\
\hline Sex (male) & -.216 & .061 & 12.443 & 1 & .000 & .806 & $0.714-0.908$ \\
\hline Age (older than 30) & .144 & .052 & 7.799 & 1 & .005 & 1.155 & $1.044-1.279$ \\
\hline Region (Vienna) & .364 & .062 & 33.918 & 1 & .000 & 1.439 & $1.273-1.626$ \\
\hline Buprenorphine & .332 & .068 & 24.190 & 1 & .000 & 1.394 & $1.221-1.591$ \\
\hline Buprenorphine/naloxone & -.037 & .105 & .126 & 1 & .723 & .964 & $0.785-1.183$ \\
\hline Slow-release morphine & .761 & .065 & 137.959 & 1 & .000 & 2.141 & $1.885-2.430$ \\
\hline Levo-methadone & .339 & .095 & 12.629 & 1 & .000 & 1.404 & $1.164-1.693$ \\
\hline
\end{tabular}

Table 3 Retention rates by substitution medication at 6 months, 1 year, and 2 years

\begin{tabular}{llll}
\hline Substitution medication & 6 months (\%) & 1 year (\%) & 2 years (\%) \\
\hline Methadone & 71 & 59 & 47 \\
Levo-methadone & 82 & 67 & 50 \\
Buprenorphine & 78 & 68 & 59 \\
Buprenorphine/naloxone & 68 & 59 & 48 \\
Slow-release morphine & 86 & 79 & 71 \\
All medications & 80 & 70 & 61
\end{tabular}

buprenorphine/naloxone (48\%), and noticeably higher for slow-release morphine (71\%) (Table 3).

\section{Discussion}

This study aimed to analyze retention rates within the Austrian substitution treatment system using data collected by the newly implemented Austrian registry. By analyzing administrative records from 4,778 patients accessing opioid substitution treatment between January 2011 and December 2012, patient characteristics associated with retention were identified. Firstly, women had significantly higher retention rates than men, which is inline with findings in other studies [11, 21,37]. Secondly, individuals who were older had significantly higher retention rates, which is also in line with a number of studies that have found older patients to be more stable and better supported than younger patients [11, 26, 38-42]. Thirdly, individuals living in Vienna have a significantly higher retention rate, in part due to the higher density of physicians well-versed in OAT as well as the shorter geographical distance between patient and treating physician, making it easier for the patients to uphold daily administration schemes [26, 43]. Lastly, different substitution medications were associated with significantly different retention rates, with SROM far exceeding all other medications [44, 45].

The Austrian one-year retention rate of $70 \%$ is among the highest retentions rates when compared to other published studies: $35.5 \%$ in British Columbia, Canada [46], 50\% in Washington, United States [47], 61\% in Ireland [11], 58\% in Baltimore, United States [21], 65.8\% in Ukraine [48], $73.9 \%$ in Tel-Aviv [49], 62\% in Las Vegas, United States [40], 53.9\% in China [26], 72.5\% in Norway [50], and $60.4 \%$ in Germany [51]. In a systematic review including 63 observational cohort studies reporting on retention rates, the median retention rate was approximately $57 \%$ at 12 months [17]. Caution is needed when comparing these retention rates however, since many factors can influence retention. Treatment programs and treatment guidelines, as well as cost and distribution models for the medications are all important in providing context when assessing retention rates between countries. OAT is the first-line treatment for opioid dependence in Austria, and facilities are generally low threshold access. Moreover, Austria is a country in which a variety of opioids is available for OAT, which is rare in an international context, and the decision to start substitution treatment depends largely upon patients and providers, unaffected by financial, regulatory, attitudinal, and logistic constraints [52-54].

The most important finding of this analysis is the significantly higher retention rate of SROM when compared to other forms of OAT. The clinical utility of SROM for opioid dependence has been reported previously and SROM is successfully used in Austria, Slovenia, Bulgaria and Switzerland $[44,55,56]$. Formulated to deliver morphine at a controlled dose over $24 \mathrm{~h}$, it is similar to other long-acting mu-opioid receptor agonists such as methadone, but has fewer cardiotoxicities, drug-drug interactions, and can be titrated more rapidly [56, 57]. A recent meta-analysis showed that SROM is equivalent to methadone in retaining patients in treatment and reducing illicit heroin use, while potentially reducing cravings [19]. SROM was also associated with higher treatment satisfaction and lower mental stress, depression, and anxiety in some studies, but with mixed evidence on quality-of life improvements compared to treatment with methadone 
or buprenorphine $[19,56,58-60]$. Additionally, maintenance treatment with SROM appears to be a clinically useful alternative treatment in patients not tolerating methadone or with inadequate withdrawal suppression [44, 61, 62]. The 2018 Canadian national clinical practice guidelines include SROM as a third-line option for patients with Opioid Use Disorder (OUD) refractory to buprenorphine and methadone [63]. In Switzerland, while the use of diacetylmorphine (approved in 1994) and buprenorphine (approved in 2002) seems to have reached a ceiling, SROM (approved in 2013) is expected to double or triple in use over the next few years [64]. As demonstrated by the Austrian registry data, SROM is broadly used in Austria and its higher retention suggests it can be effective in treatment. Of note, SROM is more expensive than methadone in Austria but substitution medication is covered by health insurance costs and therefore does not play a role at individual level. More thorough research is needed on the effectiveness of SROM in the treatment of OUD. As the majority of SROM trials are small and unblinded, further studies are necessary [65].

The present study found a 6-month buprenorphine/ naloxone retention rate of $68 \%$ and a 12 -month retention rate of $59 \%$. This is higher than what was found in a prospective, open-label, multicenter study using buprenorphine/naloxone $(n=307)$ conducted from April 2008 to August 2011 in Austria, which resulted in a 6-month retention rate of $57 \%$ and a 12 -months retention rate of $46 \%$ [66]. Buprenorphine/naloxone's lower retention rate over a decade ago is likely due to its novelty in Austria at the time, which was only approved in 2008 [28, 66]. Moreover, the development of more convenient induction methods has helped reduced barriers and expand buprenorphine/naloxone use [64, 67-69].

The in-depth overview of a complex system of care like the Austrian substitution treatment system performed in this study requires specific tools such as an online-based registry, which is highly regulated for various reasons. Most countries globally do not have such tools implemented or are not using them. Such a systematic overview is necessary to inform and control the quality of care, costs and outcomes of a system. The simple counting of adverse events such as overdose cases is not sufficient; collecting treatment data and specific outcome indicators is much more effective. The implementation of the Austrian substitution treatment registry has allowed for the systematic evaluation of treatment retention and quality of care on an individual and system-wide level.

Using registry data to analyse retention rates or different outcomes of substitution treatment is an established method in some countries $[4,37,70,71]$. It has to be kept in mind that the primary purpose of creating such a registry and supplying data to the registry is administrative. Data quality, especially with regards to "ghost cases" and unique identification, is a concern when using registry data. But often, valuable and important data that are collected by registries are not used and analyzed due to a lack of capacity or expertise. Their results are therefore not published on a regular basis and cannot provide upto-date information to providers. Resistance from health professionals, who often deem data collection as an additional workload, makes such solutions difficult to implement. However, this worked relatively well in Austria because of the simplicity and ease of the data collection using the online approach. When the Austrian substitution treatment system was migrated into an online registry (eSuchtmittel), efforts were made to ensure that the quality of the data would be sufficient enough to allow it to be used for epidemiological purposes and be extrapolated to improve patient outcomes, inform OAT services, and better manage OAT delivery. As an example of a similar system-wide approach, the Irish drug treatment services has recently developed a remote model of care using the national healthcare system for the continued assessment and ongoing provision of care to OAT patients while mitigating the risks associated with COVID-19 [72].

A main strength of this analysis is the naturalistic design of the study. A prospective naturalistic study design evaluates patients in a natural setting over time, with no attempts at intervention, thereby increasing the generalizability and external validity of the research findings. This study design has been successfully applied in previous research, including a similar study done using OAT registries in Switzerland [64]. Another strength of this analysis is its large sample size. Since all Austrian patients registered in the opioid substitution treatment are included, there was no risk of selection bias.

\section{Limitations}

Several limitations need to be considered when interpreting our data. By virtue of its naturalistic design, unlike more monitored and restricted research settings, important cofounders such as baseline substance use patterns, preferred route of substance use, co-morbid substance use patterns, medication dose, reason for treatment termination, socioeconomic indicators were unmeasured and not included in our regression model. Moreover, our analyses only used retention as the primary outcome and did not to take into account other markers of treatment success. Indeed, outcomes such as overdose, illicit drug use, abstinence are important to include when evaluating the overall quality of substitution treatment systems. In addition, we did not perform statistical analysis to account for potentially correlated outcomes 
within-individual, though only $8 \%$ of patients had multiple treatment sequences during the study period. Finally, we treated all variables as time-invariant by using the last region and last medication listed in the database. Though changes in region and medication were rare (only $16 \%$ of treatment sequences reported a change in substitution treatment), we did not perform any sensitivity analyses censoring data from patients who changed region or substitution medication during the treatment sequence.

\section{Conclusion}

The Austrian substitution registry provides a useful resource with high external validity. Though it only includes a limited set of variables, it allowed for the systematic evaluation of OAT in Austria and the significance of specific factors on treatment retention. Though difficult to compare with other studies because of the varying methodologies, the retention rate in the Austrian substitution treatment system is quite high relative to other countries. One of the most striking results of the present study is the significant superiority of SROM in terms of the treatment retention. This is encouraging data for SROM's clinical effectiveness but other aspects need to be considered and should be thoroughly researched. Developing registries similar to the one implemented in Austria would enable rapid data collection and efficient large-scale comparisons which could be analysed to improve patient outcomes.

\section{Supplementary Information}

The online version contains supplementary material available at https://doi. org/10.1186/s12954-021-00473-9.

Additional file 1: Table 1. Substitution medication by region.

Additional file 2: STROBE Checklist..

\section{Abbreviations}

OAT: Opioid agonist treatment; OUD: Opioid use disorder; SROM: Slow-release oral morphine.

\section{Authors' contributions}

Conceptualization: $\mathrm{MB}$; data curation: $\mathrm{MB}, \mathrm{CK}$, $\mathrm{AU}$; investigation: $\mathrm{MB}, \mathrm{CK}$, $\mathrm{AU}$; methodology: $M B, C K, A U$; writing \pm original draft: $M B, C K, A U, H H, M C, J N W$, MV, MRK; writing \pm review \& editing: MB, CK, AU, HH, MC, JNW, MV, MRK. All authors read and approved the final manuscript.

\section{Funding}

This article is based on analyses carried out in the framework of the Austrian "Epidemiologiebericht Drogen 2012/2013", which was funded by the Austrian Ministry of Health.

\section{Availability of data and materials}

The datasets used during the current study were collected by the Austrian substitution registry and maintained by the Federal Ministry of Health. As such, restrictions apply to the availability of these data, which were used under license for the current study and which are not publicly available. Data are however available from the authors upon reasonable request and with permission of Federal Ministry of Health.
Ethics approval and consent to participate

Approval to conduct the study was gained from the Austrian Federal Ministry of Health.

\section{Consent for publication}

This study only used administrative health data, there was no primary data collection; therefore, consent for publication from individual patients did not apply.

\section{Competing interests}

The authors declare that they have no competing interests.

\section{Author details}

${ }^{1}$ Gesundheit Österreich GmbH (GÖG), Vienna, Austria. ${ }^{2}$ Sigmund Freud University, Vienna, Austria. ${ }^{3}$ Suchthilfe Wien, Vienna, Austria. ${ }^{4}$ Zentrum Für Seelische Gesundheit, Klinikum Stuttgart, Stuttgart, Germany. ${ }^{5}$ Department of Psychiatry, University of British Columbia, Vancouver, Canada. ${ }^{6}$ Psychiatrische Klinik Münsterlingen, Münsterlingen, Switzerland. ' Addictions and Concurrent Disorders Research Group, Institute of Mental Health, University of British Columbia, David Strangway Building, 5950 University Boulevard, Vancouver, BC V6T 1Z3, Canada.

Received: 20 November 2020 Accepted: 11 February 2021

Published online: 24 February 2021

\section{References}

1. Esteban J, Gimeno C, Barril J, Aragonés A, Climent JM, de la Cruz Pellin M. Survival study of opioid addicts in relation to its adherence to methadone maintenance treatment. Drug Alcohol Depend. 2003;70(2):193-200.

2. Busch M, Haas S, Weigl M, Wirl C. Long term substitution treatment (maintenance treatment) of opioid dependent persons. GMS Health Technol Assess. 2007;3.

3. Kimber J, Palmateer N, Hutchinson SJ, Hickman M, Goldberg DJ, Rhodes T. Harm reduction among injecting drug users-evidence of effectiveness. 2010;

4. Clausen T, Anchersen K, Waal H. Mortality prior to, during and after opioid maintenance treatment (OMT): a national prospective cross-registry study. Drug Alcohol Depend. 2008;94(1-3):151-7.

5. Michels II, Stöver H, Gerlach R. Substitution treatment for opioid addicts in Germany. Harm Reduct J. 2007;4(1):5. https://doi. org/10.1186/1477-7517-4-5

6. Mattick RP, Breen C, Kimber J, Davoli M. Methadone maintenance therapy versus no opioid replacement therapy for opioid dependence. Cochrane database Syst Rev. 2009:(3).

7. Oliver P, Keen J, Rowse G, Ewins E, Griffiths L, Mathers N. The effect of time spent in treatment and dropout status on rates of convictions, cautions and imprisonment over 5 years in a primary care-led methadone maintenance service. Addiction. 2010;105(4):732-9.

8. European Centre for Disease Prevention and Control and European Monitoring Centre for Drugs, Drug and Addiction. Evidence for the effectiveness of interventions to prevent infections among people who inject drugs. Part 2: Drug treatment for preventing hepatitis C, HIV and injecting risk behaviour. [Internet]. ECDC, editor. Stockholm; 2011. http:// www.ecdc.europa.eu/en/publications/Publications/111129_TER_ECDCEMCDDA_report_part1.pdf

9. Zhang Z, Friedmann PD, Gerstein DR. Does retention matter? Treatment duration and improvement in drug use. Addiction. 2003;98(5):673-84.

10. Simpson DD, Joe GW, Brown BS. Treatment retention and follow-up outcomes in the Drug Abuse Treatment Outcome Study (DATOS). Psychol Addict Behav. 1997;11(4):294.

11. Mullen L, Barry J, Long J, Keenan E, Mulholland D, Grogan L, et al. A national study of the retention of Irish opiate users in methadone substitution treatment. Am J Drug Alcohol Abuse. 2012;38(6):551-8.

12. Sordo L, Barrio G, Bravo MJ, Indave Bl, Degenhardt L, Wiessing L, et al. Mortality risk during and after opioid substitution treatment: systematic review and meta-analysis of cohort studies. BMJ. 2017;357:j1550.

13. Cornish R, Macleod J, Strang J, Vickerman P, Hickman M. Risk of death during and after opiate substitution treatment in primary care: prospective 
observational study in UK General Practice Research Database. BMJ. 2010;341:c5475.

14. Simpson DD, Joe GW, Rowan-Szal GA. Drug abuse treatment retention and process effects on follow-up outcomes. Drug Alcohol Depend. 1997:47(3):227-35.

15. Hser Y YI, Evans E, Huang D, Anglin DM. Relationship between drug treatment services, retention, and outcomes. Psychiatr Serv. 2004;55(7):767-74.

16. Timko C, Schultz NR, Cucciare MA, Vittorio L, Garrison-Diehn C. Retention in medication-assisted treatment for opiate dependence: a systematic review. J Addict Dis. 2016;35(1):22-35.

17. O'Connor AM, Cousins G, Durand L, Barry J, Boland F. Retention of patients in opioid substitution treatment: a systematic review. PLOS ONE. 2020;15(5):1-23.

18. Kimber J, Larney S, Hickman M, Randall D, Degenhardt L. Mortality risk of opioid substitution therapy with methadone versus buprenorphine: a retrospective cohort study. Lancet Psychiatry. 2015;2(10):901-8.

19. Klimas J, Gorfinkel L, Giacomuzzi SM, Ruckes C, Socías ME, Fairbairn N, et al. Slow release oral morphine versus methadone for the treatment of opioid use disorder. BMJ Open. 2019;9(4):e025799.

20. Havens JR, Latkin CA, Pu M, Cornelius LJ, Bishai D, Huettner S, et al. Predictors of opiate agonist treatment retention among injection drug users referred from a needle exchange program. J Subst Abuse Treat. 2009;36(3):306-12. https://doi.org/10.1016/j.jsat.2008.07.002.

21. Kelly SM, O'Grady KE, Mitchell SG, Brown BS, Schwartz RP. Predictors of methadone treatment retention from a multi-site study: a survival analysis. Drug Alcohol Depend. 2011;117(2-3):170-5. https://doi.org/10.1016/j. drugalcdep.2011.01.008.

22. Sarasvita R, Tonkin A, Utomo B, Ali R. Predictive factors for treatment retention in methadone programs in Indonesia. J Subst Abuse Treat. 2012:42(3):239-46. https://doi.org/10.1016/j.jsat.2011.07.009.

23. Villafranca SW, McKellar JD, Trafton JA, Humphreys K. Predictors of retention in methadone programs: a signal detection analysis. Drug Alcohol Depend. 2006;83(3):218-24.

24. Grella $C E$, Wugalter $S E$, Anglin MD. Predictors of treatment retention in enhanced and standard methadone maintenance treatment for HIV risk reduction. J Drug Issues. 1997;27(2):203-24.

25. Mertens JR, Weisner CM. Predictors of substance abuse treatment retention among women and men in an HMO. Alcohol Clin Exp Res. 2000;24(10):1525-33.

26. Yang $F$, Lin $P, L i Y, H e ~ Q$, Long $Q$, Fu X, et al. Predictors of retention in community-based methadone maintenance treatment program in Pearl River Delta, China. Harm Reduct J. 2013;10(1):3.

27. Morin KA, Eibl JK, Gauthier G, Rush B, Mushquash C, Lightfoot NE, et al. A cohort study evaluating the association between concurrent mental disorders, mortality, morbidity, and continuous treatment retention for patients in opioid agonist treatment (OAT) across Ontario, Canada, using administrative health data. Harm Reduct J. 2020;17(1):51. https://doi. org/10.1186/s12954-020-00396-X.

28. European Monitoring Centre for Drugs and Drug Addiction (EMCDDA). Drug policy profile: Austria [Internet]. Luxembourg; 2014. https:// www.emcdda.europa.eu/system/files/publications/777/TDAU14004E NN 469059.pdf

29. Horvath I, Anzenberger J, Busch M, Schmutterer I, Tanios A, Weigl M. Bericht zur Drogensituation 2019. 2019;

30. Haltmayer H. Oral Substitution Treatment in Austria—-the role of GPs [Internet]. 2010. https://www.emcdda.europa.eu/attachements.cfm/ att_118398_EN_Dr Haltmayer_Austria.pdf

31. Legal Information System of the Republic of Austria. Consolidated federal law: Entire legal provision for the Narcotics Act, version of January 27, 2021 [Internet]. 2021. https://www.ris.bka.gv.at/GeltendeFassung . wxe? Abfrage $=$ Bundesnormen\&Gesetzesnummer $=10011040$

32. Legal Information System of the Republic of Austria. Consolidated federal law: Entire legal provision for further training ordinance on opioid substitution, version of January 27, 2021. 2021.

33. EMCDDA. Mortality among drug users: Guidelines for carrying out, analysing and reporting key figures [Internet]. Lisbon; 2012. http://www. emcdda.europa.eu/attachements.cfm/att_192545_EN_MortalityCohort sGuidelines2012.pdf

34. SPSS Inc. SPSS Statistics, Version 17.0. Chicago, United States; 2008.
35. Knottnerus A, Tugwell P. STROBE-a checklist to strengthen the reporting of observational studies in epidemiology. J Clin Epidemiol. 2008;61(4):323.

36. European Monitoring Centre for Drugs and Drug Addiction (EMCDDA). Austria, Country Drug Report 2017. Luxembourg; 2017.

37. Deck D, Carlson MJ. Retention in publicly funded methadone maintenance treatment in two western states. J Behav Health Serv Res. 2005;32(1):43-60.

38. Torrens M, Castillo C, Pérez-Solá V. Retention in a low-threshold methadone maintenance program. Drug Alcohol Depend. 1996;41(1):55-9.

39. Ren J, Ning Z, Asche C, Zhuang M, Kirkness CS, Ye X, et al. Determinants on compliance of methadone maintenance treatment in Shanghai, China. Value Heal. 2013;16(3):A194.

40. Peles E, Linzy S, Kreek MJ, Adelson M. One-year and cumulative retention as predictors of success in methadone maintenance treatment: a comparison of two clinics in the United States and Israel. J Addict Dis. 2008;27(4):11-25.

41. Sharifa Ezat WP, Noor Azimah H, Rushidi R, Raminder K, Ruhani I. Compliance towards methadone maintenance therapy and its associated factors in Selangor primary care centers and Kuala Lumpur hospital. Med J Malaysia. 2009;64(1):65-70.

42. D'Ippoliti D, Davoli M, Perucci CA, Pasqualini F, Bargagli AM. Retention in treatment of heroin users in Italy: the role of treatment type and of methadone maintenance dosage. Drug Alcohol Depend. 1998;52(2):167-71.

43. Beardsley K, Wish ED, Fitzelle DB, O'Grady K, Arria AM. Distance traveled to outpatient drug treatment and client retention. J Subst Abuse Treat. 2003;25(4):279-85.

44. BeckT, Haasen C, Verthein U, Walcher S, Schuler C, Backmund M, et al. Maintenance treatment for opioid dependence with slow-release oral morphine: a randomized cross-over, non-inferiority study versus methadone. Addiction. 2014;109(4):617-26.

45. Jegu J, Gallini A, Soler P, Montastruc J, Lapeyre-Mestre M. Slow-release oral morphine for opioid maintenance treatment: a systematic review. $\mathrm{Br}$ J Clin Pharmacol. 2011;71(6):832-43.

46. Socías ME, Wood E, Kerr T, Nolan S, Hayashi K, Nosova E, et al. Trends in engagement in the cascade of care for opioid use disorder, Vancouver, Canada, 2006-2016. Drug Alcohol Depend. 2018;189:90-5.

47. Amiri S, Hirchak K, Lutz R, McDonell MG, McPherson SM, Roll JM, et al. Three-year retention in methadone opioid agonist treatment: a survival analysis of clients by dose, area deprivation, and availability of alcohol and cannabis outlets. Drug Alcohol Depend. 2018;193:63-8.

48. Dumchev K, Dvoryak S, Chernova O, Morozova O, Altice FL. Retention in medication-assisted treatment programs in Ukraine-Identifying factors contributing to a continuing HIV epidemic. Int J Drug Policy. 2017:48:44-53.

49. Peles E, Schreiber S, Adelson M. Factors predicting retention in treatment: 10-year experience of a methadone maintenance treatment (MMT) clinic in Israel. Drug Alcohol Depend. 2006;82(3):211-7.

50. Bukten A, Skurtveit S, Waal H, Clausen T. Factors associated with dropout among patients in opioid maintenance treatment (OMT) and predictors of re-entry. A national registry-based study. Addict Behav. 2014;39(10):1504-9.

51. Soyka M, Apelt SM, Lieb M, Wittchen H-U. One-year mortality rates of patients receiving methadone and buprenorphine maintenance therapy: a nationally representative cohort study in 2694 patients. J Clin Psychopharmacol. 2006;26(6):657-60.

52. Sharma A, Kelly SM, Mitchell SG, Gryczynski J, O'Grady KE, Schwartz RP. Update on barriers to pharmacotherapy for opioid use disorders. Curr Psychiatry Rep. 2017;19(6):35.

53. Gertner AK, Robertson AG, Jones H, Powell BJ, Silberman P, Domino ME. The effect of Medicaid expansion on use of opioid agonist treatment and the role of provider capacity constraints. Health Serv Res. 2020;55(3):383-92.

54. Larney S, Peacock A, Leung J, Colledge S, Hickman M, Vickerman P, et al. Global, regional, and country-level coverage of interventions to prevent and manage HIV and hepatitis $C$ among people who inject drugs: a systematic review. Lancet Glob Heal. 2017;5(12):e1208-20. https://doi. org/10.1016/S2214-109X(17)30373-X.

55. Wells C, Jones S. Sustained Release Oral Morphine, Injectable Hydromorphone, and Prescription Diacetylmorphine for Opioid Use Disorder: Clinical and. Ottawa; 2017. 
56. Hämmig R, Köhler W, Bonorden-Kleij K, Weber B, Lebentrau K, Berthel T, et al. Safety and tolerability of slow-release oral morphine versus methadone in the treatment of opioid dependence. J Subst Abuse Treat. 2014;47(4):275-81.

57. Kimmel S, Bach P, Walley AY. Comparison of Treatment Options for Refractory Opioid Use Disorder in the United States and Canada: a Narrative Review. J Gen Intern Med. 2020;1-9.

58. Giacomuzzi S, Kemmler G, Ertl M, Riemer Y. Opioid addicts at admission vs. slow-release oral morphine, methadone, and sublingual buprenorphine maintenance treatment participants. Subst Use Misuse. 2006:41(2):223-44.

59. Eder H, Jagsch R, Kraigher D, Primorac A, Ebner N, Fischer G. Comparative study of the effectiveness of slow-release morphine and methadone for opioid maintenance therapy. Addiction. 2005;100(8):1101-9.

60. Clark NKK, Lintzeris N, Ritter A, Whelan G. A randomised trial of once-daily slow-release oral morphine versus methadone for heroin dependence. Drug Alcohol Depend. 2002;66:s33.

61. Bond AJ, Reed KD, Beavan P, Strang J. After the randomised injectable opiate treatment trial: Post-trial investigation of slow-release oral morphine as an alternative opiate maintenance medication. Drug Alcohol Rev. 2012;31(4):492-8

62. Kastelic A, Dubajic G, Strbad E. Slow-release oral morphine for maintenance treatment of opioid addicts intolerant to methadone or with inadequate withdrawal suppression. Addiction. 2008;103(11):1837-46.

63. Bruneau J, Ahamad K, Goyer MĖ, Poulin G, Selby P, Fischer B, et al. Management of opioid use disorders: a national clinical practice guideline. CMAJ. 2018;190(9):E247-57.

64. Nordt C, Vogel M, Dey M, Moldovanyi A, Beck T, Berthel T, et al. One size does not fit all—evolution of opioid agonist treatments in a naturalistic setting over 23 years. Addiction. 2019;114(1):103-11.

65. Socias ME, Wood E, Dong H, Brar R, Bach P, Murphy SM, et al. Slow release oral morphine versus methadone for opioid use disorder in the fentanyl era (pRESTO): Protocol for a non-inferiority randomized clinical trial. Contemp Clin Trials. 2020;91:105993.

66. Jagsch R, Fischer G, Köchl B, Unger A. Buprenorphin/Naloxon-Ergebnisse aus dem niedergelassenen Bereich. Suchttherapie. 2013;14(02):84-91.

67. Hämmig R, Kemter A, Strasser J, von Bardeleben U, Gugger B, Walter M, et al. Use of microdoses for induction of buprenorphine treatment with overlapping full opioid agonist use: the Bernese method. Subst Abuse Rehabil. 2016;7:99-105.

68. Klaire S, Zivanovic R, Barbic SP, Sandhu R, Mathew N, Azar P. Rapid microinduction of buprenorphine/naloxone for opioid use disorder in an inpatient setting: a case series. Am J Addict. 2019;28(4):262-5.

69. Rozylo J, Mitchell K, Nikoo M, Durante SE, Barbic SP, Lin D, et al. Case report: Successful induction of buprenorphine/naloxone using a microdosing schedule and assertive outreach. Addict Sci Clin Pract. 2020;15(1):1-6.

70. Burns L, Randall D, Hall WD, Law M, Butler T, Bell J, et al. Opioid agonist pharmacotherapy in New South Wales from 1985 to 2006: patient characteristics and patterns and predictors of treatment retention. Addiction. 2009;104(8):1363-72.

71. Bukten A, Røislien J, Skurtveit S, Waal H, Gossop M, Clausen T. A day-byday investigation of changes in criminal convictions before and after entering and leaving opioid maintenance treatment: a national cohort study. BMC Psychiatry. 2013;13(1):262

72. Crowley D, Delargy I. A national model of remote care for assessing and providing opioid agonist treatment during the COVID-19 pandemic: a report. Harm Reduct J. 2020;17(1):49. https://doi.org/10.1186/s12954-02000394-z.

\section{Publisher's Note}

Springer Nature remains neutral with regard to jurisdictional claims in published maps and institutional affiliations.
Ready to submit your research? Choose BMC and benefit from:

- fast, convenient online submission

- thorough peer review by experienced researchers in your field

- rapid publication on acceptance

- support for research data, including large and complex data types

- gold Open Access which fosters wider collaboration and increased citations

- maximum visibility for your research: over $100 \mathrm{M}$ website views per year

At BMC, research is always in progress.

Learn more biomedcentral.com/submissions 